\section{Confirmation of the validity of using birth MCV for the diagnosis of alpha thalassemia trait}

\author{
Akram M. Al-Hilali, Aisha M. Al-Jallaf, \\ Sajida Chunkasseril
}

Hematology Unit, Pathology Department, Dubai Hospital, Dubai, UAE

\section{Abstract}

Thirty-four blood samples of neonates in Dubai, UAE, with an MCV below $90 \mathrm{fL}$ were checked by high performance liquid chromatography (HPLC) for hemoglobin variants to confirm a previous study carried out in Western Province of Saudi Arabia which showed a very high predictive index of such MCV for alpha ( $\alpha$-) thalassemia minor (ATM). MCH below $30 \mathrm{pg}$ was an additional factor which supported such a prediction. The Dubai study confirmed the original finding with $100 \%$ of such neonates showing $\mathrm{Hb}$ Barts band. A control group of 26 neonates with an MCV between 90 and $95 \mathrm{fl}$ showed Hb Barts in only 11 cases (42.3\%). Of these, 6 (23.1\%) were preterm babies, expected to have higher MCV. Five cases (19.2\%) had an MCH below $30 \mathrm{pg}$, though MCV was 90 or higher. Three of the preterm babies also had MCH below 30 . The study confirmed the Saudi results in neonates. It seems very highly probable that a term neonate with MCV below 90 and MCH below 30 has ATM.

\section{Introduction}

The presence of $\mathrm{Hb}$ Barts in blood at birth is a finding in $\alpha$-thalassemia trait, intermedia (HbH disease) and major (hydrops fetalis). ${ }^{1,2}$ Diagnosis of $\alpha$-thalassemia major is not a problem and it is incompatible with life $^{3}$ as most of the hemoglobin will be Barts. Neonates with $\alpha$-thalassemia intermedia have $\mathrm{HbF}, \mathrm{HbA}$ and $\mathrm{Hb}$ Barts, usually more than $15 \%{ }^{4}$ This condition is easy to diagnose later in life, even if not investigated at birth, due to the presence of $\mathrm{HbH}^{6}$

The problem lies with $\alpha$-thalassemia trait, single or double gene deletion types. Most of these cases have normal HbA2 levels if checked after the age of six months,${ }^{6,7,8}$ though red cell indices are thalassemic. This group, which makes up the bulk of gene carriers, will be difficult to confirm by $\mathrm{Hb}$ electrophoresis (HBEP) or by HPLC in childhood and adult life. If one can check HBEP or HPLC at birth then presence of $\mathrm{Hb}$ Barts would put the diagnosis on solid grounds. Hb Barts disappears a few weeks after birth.

It is too expensive to perform HPLC or HBEP for all neonates, even in areas where frequency of the $\alpha$-thalassemia gene is high. So, if we can predict, with cheap tests, the presence of $\alpha$-thalassemia then Hb separation can be performed for the highly probable cases only. This issue was addressed by work carried out in Thailand, ${ }^{9}$ and in Jeddah, Saudi Arabia a few years ago. ${ }^{6} \mathrm{MCV}$ below 90 and MCH below 30 were found to be of very high predictive value in the Jeddah study.

There was a need to repeat the study in another setting, where thalassemics are of variable ethnic groups, like in Dubai. $\alpha$-thalassemia is present in the UAE nationals and residents of Iranian, Arab, Pakistani and Filipino origins in Dubai and it was expected that neonates in such a population would make a good sample for repetition of the study and confirmation of the validity of using the MCV and $\mathrm{MCH}$ as predictive parameters in individuals of various ethnic groups.

\section{Materials and Methods}

All full blood counts (FBC) performed for neonates were checked. Counts were performed using a Coulter machine model LH7D1 (Beckman Coulter, Brea, Ca, USA). Thirty-four consecutive neonates, with MCV below $90 \mathrm{fL}$ were checked by HPLC, using Waters 2695 machine (Milford, Ma, USA), and short $\beta$-thalassemia program, to look for $\mathrm{Hb}$ Barts band.

Blood films of all babies included in the study were checked by the hematopathologist for red cell morphology. FBCs had not been ordered for these babies because of any suspicion of thalassemia. They were random and judged to be necessary by the attending neona-

Table 1. Results on cord blood of test group.

\begin{tabular}{lccccc} 
Hb Barts & & MCV & & MCH & \\
& $<90$ & $\geq 90$ & $<30$ & $\geq 30$ & Total cases \\
Positive & 34 & 0 & 33 & 1 & 34 \\
$\%$ & 100 & 0 & 97 & 3 & \\
Negative & 0 & NA & 0 & 0 & 0 \\
& 0 & & 0 & 0 & \\
\hline
\end{tabular}

Table 2. Results on cord blood of test group.

\begin{tabular}{|c|c|c|c|c|c|}
\hline Hb Barts & & & & $\mathrm{ICH}$ & \\
\hline & $<90$ & $\geq 90$ & $<30$ & $\geq 30$ & Total cases \\
\hline Positive & NA & 11 & 7 (3 preterm) & 4 (3 preterm) & 11 \\
\hline$\%$ & & 42.3 & 26.9 & 15.3 & 42.3 \\
\hline $\begin{array}{l}\text { Negative } \\
\%\end{array}$ & NA & $\begin{array}{c}15 \\
57.6\end{array}$ & $\begin{array}{l}0 \\
0\end{array}$ & $\begin{array}{l}15 \\
67.6\end{array}$ & $\begin{array}{c}15 \\
57.6\end{array}$ \\
\hline
\end{tabular}

Correspondence: Akram Al-Hilali, Consultant Hematopathologist, Dubai Hospital, Dubai, UAE. E-mail: akramhilali@yahoo.com

Key words: MCV, MCH, Hb Barts, high performance liquid chromatography.

This work was presented in part at the 32nd Congress of the International Society of Haematology held in Bangkok, Thailand in October 2008.

Received for publication: 18 June 2009. Revision received: 17 September 2009.

Accepted for publication: 21 October 2009.

This work is licensed under a Creative Commons Attribution 3.0 License (by-nc 3.0).

(C)Copyright A.M. Al-Hilali et al., 2009

Licensee PAGEPress, Italy

Hematology Reviews 2009; 1:e20

doi:10.4081/hr.2009.e20

tologists for various reasons.

As a control group, 26 neonates, who had MCV between 90 and $95 \mathrm{fL}$ were also checked by HPLC. Again, these were not selected and all consecutive cases with such an MCV level were included into the control group. It took eight months to collect the entire test and control cases because only a minority of neonates in Dubai have blood counts checked.

\section{Results}

All individuals in the test group had MCV below $90 \mathrm{fL}$ (mean 85.35, range 77-88.9). $\mathrm{MCH}$ was below 30 in $33 / 34$ patients (97\%). One patient (3\%) had an MCH of 31.1 pg. Mean MCH was 27.82 and range 25.1-31.1.

$\mathrm{Hb}$ Barts was demonstrated in all the 34 cases $(100 \%)$. It ranged from a trace (less than 
$1 \%$ ) to $10.6 \%$ (mean $4.65 \%$ ). The $10.6 \%$ figure was obtained in the baby with the lowest MCV (77) and MCH (25.1) (Table 1), who had Hb level of 12.5 and later proved to have $\mathrm{Hb} \mathrm{H}$ disease. MCV in the control group ranged from 90.1 to $94.8 \mathrm{fL}$ (mean 92.27) and $\mathrm{MCH}$ from 28.7 to 31.7 (mean 30.33). Hb Barts was demonstrated in 11 cases (42.3\%). It ranged from $2-6 \%$ in those cases. Fifteen cases (57.6\%) were negative for $\mathrm{Hb}$ Barts. Analyzing the 11 Barts-positive cases further showed that 7 of them had MCH below 30 and 6 were preterm (3 of them had MCH below 30). Only one baby (3.8\%) out of the 26 controls and positive Barts had MCH above 30 and was full term (Table 2). Blood films of all babies included in the test group showed numerous target cells and microcytosis, but no signs of active hemolysis.

\section{Discussion}

After the work carried out in Jeddah, Saudi Arabia, ${ }^{6}$ where the population is basically local with a low expatriate mix, as well as some variation in the origin of the local population itself, it was thought useful to the medical literature to repeat the study at another site to confirm the remarkable results of the original study. Medical literature does mention that $\alpha$-thalassemia trait individuals are born with microcytosis. ${ }^{5,10,11}$ However, there is no clear demarcation of the level of MCV and MCH where one can expect, with high confidence, to find $\alpha$ thalassemia. ${ }^{3,5,11}$ The work carried out in Thailand $^{9}$ took the MCV cut-off value of 95 . In our experience, in both works performed in Jeddah and in Dubai a MCV cut-off value of 95 will give a lot of negative cases and make the need for HPLC/HBEP much higher, thus increasing the cost while one of the objectives of this scheme is to lower costs.

The advantage of using MCV and MCH levels is that these values are easily available from a simple automated blood count (FBC). If one can prove that there are limit levels for these two parameters which carry a high probability of $\alpha$-thalassemia trait and $\mathrm{HbH}$ disease, then there will be a small proportion of patients for whom one needs to perform $\mathrm{Hb}$ separation procedure, by alkaline electrophoresis or HPLC, to demonstrate Hb Barts, and thus prove $\alpha$-thalassemia presence. It is confirmed from this study that if MCV is below $90 \mathrm{and} / \mathrm{or} \mathrm{MCH}$ is below 30 there is a high probability of over $95 \%$ that the case is $\alpha$-thalassemia trait. MCV may be above 90 if the baby is born premature. In such cases one can extend the MCV level to 95, whether or not

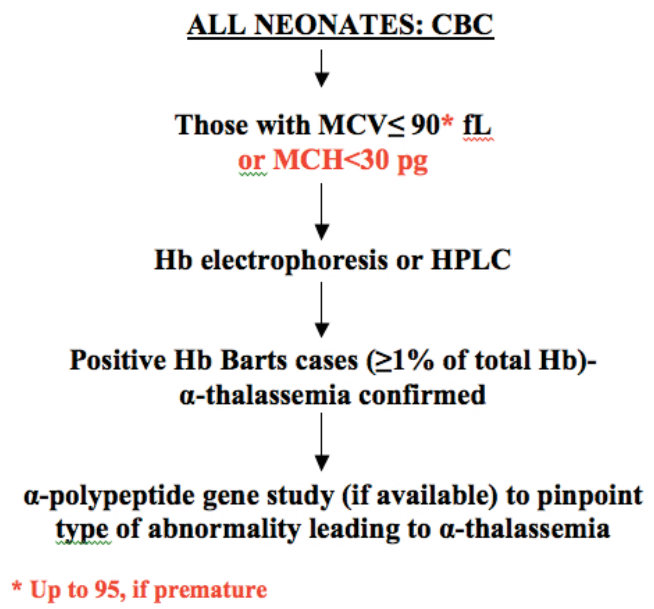

Figure 1. Investigational scheme for $\alpha$-thalassemia screening of neonates.

Up to 95 , if premature

$\mathrm{MCH}$ is below $30 \mathrm{pg}$. It is noteworthy that $\mathrm{Hb}$ Barts is not only a diagnostic finding for $\alpha$-thalassemia, but it tends to disappear a few weeks after birth. ${ }^{10}$ Trying to confirm $\beta$-thalassemia trait at a later age, when suspicion is raised by low red cell indices leading to erythrocytosis, hematologists first resort to HBEP or HPLC, looking for low $\mathrm{HbA} 2$. However, low $\mathrm{HbA} 2$ is not a common finding in this condition. ${ }^{6}$ Also, low $\mathrm{Hb}$ A2 is found in other conditions, like $\beta$ thalassemia. Iron deficiency anemia may also lower $\mathrm{HbA} 2$ to below normal level. ${ }^{12-14}$ Failing to confirm the condition by this routine test, as in the majority of cases, one can try molecular studies on the $\alpha$-polypeptide gene to look for deletions or mutations known to lead to $\alpha$-thalassemia trait. These deletions and mutations are so numerous ${ }^{5,15,16}$ that, in practice, laboratories only try the common local deletions or mutations, using the proper probes for them, if these are known from previous studies. In a mixed population the task will be difficult, as one can imagine. The cost of these molecular tests is certainly higher than $\mathrm{Hb}$ separation studies. In parts of the world where $\alpha$-thalassemia gene is of high frequency, the cost will be enormous if one wants to diagnose all carriers. It should be remembered that most countries harboring a high frequency for the gene are also poor in resources. ${ }^{17}$ The simple strategy we are recommending, proven by the two studies in two different locations, is valid and is recommended by the authors for WHO and local public health schemes to establish the diagnosis and gene frequency. Further studies are being considered to try to split populations with one, two and three gene deletions/mutations from levels of MCV and MCH caused by them and the HPLC performed as a result of obtaining the low MCV and $\mathrm{MCH}$ figures. The simple investigational scheme that we suggest to be followed for the $\alpha$-thalassemia screening of neonates is shown in Figure 1.

\section{References}

1. Weatherall DJ, Clegg JB. The thalassemia syndrome 4th edition. Blackwell Science, 0xford, UK 2004.

2. Weatherall DJ. The molecular basis for phenotypic variability of the common thalassemias. Mol Med Today 1995;1:15-20.

3. Henthorn J, Anionwu E, Brozovic M. Screening cord blood for sickle haemoglobinopathies. BMJ 1984; 289:479-80.

4. Higgs DR. Alpha thlassemias. Baillieres Clin Haematol 1993;6:117-50.

5. Higgs DR, Bowden DK. Clinical and Laboratory Features of alpha-thalassemia Syndromes. In: Steinberd MH, Forget PG, Higgs DR, Nagel RL, eds. Disorders of Hemoglobin: Genetic, Pathophysiology and Clinical Management. Cambridge University Press, Cambridge, UK. 2001: p.431-69.

6. Al-Hilali A, Abu Saud K, Soufi S, La Cock C. Birth MCV \& MCH are very reliable predictors of the presence or absence of alpha thalassaemia in the neonate. Clin Med Blood Dis 2009;2:1-4.

7. Kyriacou K, Kyrri A, Kalogirou E, et al. Hb Bart's level in cord blood and alpha thalassemia mutations in Cyprus. Hemoglobin 2000;24:171-80.

8. Rugless MJ, Fisher CA, Stephens AD, et al. Hb Bart's in cord blood: an accurate indicator of alpha thalassemia. Hemoglobin 2006;30:57-62.

9. Tritipsombat J, Sanchaisuriya K, Fucharoen $\mathrm{G}$, et al. Hb profiles and hematologic features of thalassemic newborns: application to screening of $\alpha$-thalassemia and Hb E. Arch Pathol Lab Med 2008;132:173945.

10. El-Hazmi MAF. Haemoglobinopathies, thalassaemias and enzymopathies in Saudi Arabia: the present status. Acta Haematol 


\section{7;78:130-4.}

11. Sanchaisuriya K, Fucharoen $S$, Fucharoen $\mathrm{G}$, et al. A reliable screening protocol for thalassemia and hemoglobinopathies in pregnancy. Am J Clin Pathol 2005;123:1138.

12. Wasi P, Disthasongchan P, Na-Nakron S. The effect of iron deficiency on level of haemoglobins A2 and E. J. Lab Clin Med 1968;71:85-91.

13. Steiner J, Marti HR, Dean D. Decreased
Hemoglobin A2 concentration in iron deficiency anemia. Acta Haematol 1971;45: 77-81.

14. Kuczynski A. The relationship between the serum iron concentration and erythrocyte haemoglobin A2 level. J Med 1971;2: $136-42$.

15. Old JM. DNA-based diagnosis of hemoglobin disorders. In: Steinberg MH, Forget PG, Higgs DR, Nagel RL, eds. Disorders of Hemoglobin: Genetic, Pathophysiology and Clinical Management. Cambridge University Press, Cambrige, UK. 2001: 941-57.

16. Vulliamy T, Kaeda J. Molecular Techniques. In: Dacie \& Lewis Practical Haematology, London: Churchill Livingstone, 9th Ed. 2002.p.493-525.

17. Weatherall DJ, Clegg JB. Inherited hemoglobin disorders: an increasing global health problem. Bull World Health Organ 2001;79:704-12. 